\title{
A transversalidade dos direitos humanos na gestão pública ${ }^{1}$
}

\author{
Maria do Rosário Nunes
}

Durante um largo período, no Estado, nós não trabalhamos planejamento, nós não trabalhamos com metas. Isso foi agravado no período em que se primou pela diminuição do tamanho do Estado, pela aplicabilidade de pressupostos que na verdade não tinham a ver com os compromissos humanos do Estado, com os compromissos de promoção e defesa dos direitos humanos. A Constituição de 1988 oferece o patamar fundamental para o Brasil, mas os anos que se seguiram estruturaram o modelo de gestão de diminuição do Estado, que não permitiu a execução das políticas e dos compromissos democráticos estruturados pela própria Carta Magna, considerando a declaração universal, o pacto sobre os direitos civis e políticos, mas também os direitos econômicos, sociais e culturais.

Nos últimos 10 anos, não ao acaso, estamos invertendo essa lógica, pensando gestão associada a um projeto de desenvolvimento, a uma perspectiva política, a um entendimento político de que gestão é ferramenta essencial para a qualidade de serviços públicos de um Estado que precisa democratizar-se para atender às necessidades de milhões de brasileiros e brasileiras que estiveram durante muitos anos à margem das garantias fundamentais. 
Precisamos estabelecer um encontro entre a capacidade de gestão, a qualidade da gestão e as práticas políticas em direitos humanos. Temos que compreender que as estruturas de gestão devem ser absolutamente transparentes e claras, além de permitir a participação direta da sociedade. É fundamental entendermos essas ferramentas transformadoras e participativas da gestão, cuja qualidade final tem a ver com a qualidade do atendimento das necessidades humanas e da superação das violências praticadas pelo Estado brasileiro em toda a sua estrutura federativa. Não apenas no plano do Poder Executivo, mas dos demais poderes também.

Portanto, temos um interesse claro: democratizar ainda mais o Estado e constituir, por meio dos gestores públicos, bases sólidas para se atingir a desejada qualidade, a partir da perspectiva dos direitos humanos. O Presidente Lula, no seu período de governo, fez uma junção que para alguns parecia impossível, entre o desenvolvimento econômico e as garantias sociais. O grande desafio é erradicarmos a pobreza. Para isso, trabalhamos aceleradamente o tema das terras indígenas, das terras quilombolas, enfrentamos o tema da democratização das universidades, ampliamos o acesso a serviços públicos, enfrentamos o trabalho escravo, entre tantos outros avanços. Essas medidas foram desencadeadas pelo olhar e pela opção política do Presidente Lula, ao determinar que o crescimento econômico só tinha sentido para o Brasil se associado à superação das violações de direitos, fazendo com que as pessoas pudessem acessar serviços públicos e direitos aos quais elas não tinham tido acesso até então. Milhões de brasileiros foram incluídos. Hoje o desafio deste atual período é pensarmos em chegar aonde ainda não conseguimos chegar, porque infelizmente as violações de direitos humanos permanecem e desequilibram as nossas certezas. A mortalidade juvenil, as violações dos direitos dos indígenas, as mortes no campo, os grupos de extermínio no interior, as milícias nas cidades grandes são desafios permanentes, que fazem com que o Brasil esteja na ponta dos números de mortes por causas violentas, em que pese a trajetória que estamos cumprindo de assegurarmos direitos constitucionalmente.

Por isso, enfrentamos permanentemente esta cultura da desinformação, assim como buscamos as conexões que existem entre direitos humanos, democracia e paz, como Norberto Bobbio nos apresenta em sua obra $A$ Era dos Direitos. O filósofo italiano revela o significado contemporâneo de direitos humanos, que, antes mesmo da Declaração Universal, pode ser identificado nas declarações americanas, de 1776, ou na Revolução Francesa, em 1789. Os significados que essas declarações trouxeram são fundamentais para a noção de direitos, noção de direitos imprescritíveis, noção de direitos inalienáveis. Mas é somente com as grandes guerras que vamos percebendo e organizando os direitos humanos não apenas como princípios gerais, mas agora como sistemas sistemas internacionais, sistemas regionais, no nosso caso no âmbito da Organização dos Estados Americanos, mas que tem suas contrapartes no território europeu, na África etc.

O sistema interamericano é referência fundamental. A partir da Carta de São José da Costa Rica, temos um conceito formado a partir de um amplo espectro de possibilidades que precisam ser permanentes do ponto de vista sociológico, político, filosófico, econômico e geográfico. São questões relacionadas, nos dias 
atuais, ao meio ambiente ou à biotecnologia, pressupostos éticos que orientam todo conhecimento, a ciência, a produção teórica, as possibilidades de reflexão sobre quem somos, e como nos relacionamos com o meio em que estamos. É hora de questionarmos: qual o sentido de humanidade? Que, aliás, é uma questão integrante do preâmbulo da Declaração Universal de Direitos Humanos, numa das expressões que eu considero das mais bonitas, quando chama a atenção para nos posicionarmos como parte de uma família humana e, portanto, para além das fronteiras geográficas nacionais.

O servidor público tem uma tarefa decisiva para assegurar a universalidade dos direitos humanos. Principalmente porque seu princípio ético é um compromisso intrínseco de fazer todo o possível pela dignidade humana. É estar movido pela igualdade de direitos e não por hierarquias. Entre os elementos constitutivos desses pressupostos éticos, reside a observância dos tratados, os pactos e, especialmente, a Declaração Universal dos Direitos Humanos. O servidor público deve agir a partir desses pressupostos, e não apenas o servidor da Secretaria de Direitos Humanos, mas o servidor lotado no Ministério da Justiça, Defesa, Educação, ou qualquer outro órgão do nosso governo.

É importante sabermos que direitos humanos não é um tema estático. Por exemplo, até bem pouco tempo o tema dos mortos e desaparecidos era tratado apenas pelas famílias. Eram as famílias dos mortos e desaparecidos que erguiam os seus nomes, os seus cartazes e que não nos deixaram esquecer. Temos que fazer essa referência com muita gratidão. No âmbito das Nações Unidas, é muito recente a afirmação do direito à memória, à verdade e à justiça como um elemento constitutivo.
O Brasil tem uma importância grande, em que pese nosso país ter sido um dos últimos a viverem ditaduras e a terem instituído uma Comissão da Verdade. Aqui vale, portanto, pensarmos que as políticas de direitos humanos devem ser aperfeiçoadas permanentemente, porque as violações também ocorrem de forma constante. Estamos no atual período debatendo, por exemplo, as questões relacionadas à população LGBT no mundo. Debatemos, por exemplo, resoluções no âmbito dos direitos dos idosos. No âmbito dos direitos das pessoas com deficiência, aprovamos, com status de emenda constitucional, a Convenção das Nações Unidas para os Direitos da Pessoa com Deficiência. De forma geral, todos os tratados e convenções internacionais sobre direitos

"Temos que compreender que as estruturas de gestão devem ser absolutamente transparentes e claras, além de permitir a participação direta da sociedade."

humanos aprovados por $3 / 5$ dos votos recebem equivalência de emenda constitucional. Isso não é pouca coisa.

O Brasil está na terceira edição do Programa Nacional de Direitos Humanos, o chamado PNDH-3, que deve ser estudado com profundidade pelos gestores públicos. O PNDH-3 dialoga com cada uma das temáticas dos direitos humanos. Ele é uma base fundamental porque cumpre diretrizes internacionais, que surgiram justamente para superar uma lacuna, em termos de planejamento em matéria de direitos humanos, metas claras, 
prazos e orientações sobre como chegar a essas metas. Desde que reconstruímos a democracia no Brasil e participamos do sistema interamericano, estabelecemos compromissos perante a comunidade internacional. Compromissos diante dos povos do mundo, compromisso diante das nações, mas compromissos para serem cumpridos em primeiríssimo lugar diante da nossa própria população.

Temos que lidar com a participação das pessoas como algo fundamental. $\mathrm{O}$ lema do movimento de pessoas com deficiência é "nada sobre nós sem nós", e isso vale para cada segmento populacional. A conferência de pessoas com deficiência foi uma grande aula de gestão para todos nós. Um ano antes, já tínhamos assegurado os quartos adaptados para receber os participantes. Tínhamos os números de pessoas; a conferência estava realizando-se nos Estados e nos Municípios. Mobilizamos o Brasil em torno da participação das pessoas com deficiência e produzimos uma

\section{“O servidor público tem uma tarefa decisiva para assegurar a universalidade dos direitos humanos. ... compromisso intrínseco de fazer todo o possível pela dignidade humana."}

conferência totalmente acessível. Mas ao longo da conferência, deparamo-nos com menos quartos do que pessoas com deficiência. Como isso aconteceu? Vieram mais pessoas com deficiência do que esperávamos, pois muitos dos acompanhantes escolhidos também eram pessoas com deficiência - não contávamos com isso. E quem de nós ia dizer que uma pessoa com deficiência não podia ser acompanhada de outra pessoa com deficiência? $\mathrm{E}$ a equipe de gestão teve que resolver. Outro exemplo foi a aprovação pelo Conselho Nacional do Idoso de uma maioria das pessoas com mais de sessenta anos como participantes na respectiva conferência. A propósito, a Conferência dos Direitos da Pessoa Idosa nos ensinou muito sobre como receber as pessoas. Muitos tinham oitenta anos, alguns mais do que isso e, portanto, naturalmente, sua mobilidade era reduzida. $\mathrm{O}$ tipo de atendimento muda, a atenção que os gestores precisam dedicar a esse público não é a mesma dada, por exemplo, a uma conferência da juventude. O tipo de planejamento é outro. Na última conferência dos direitos da criança e do adolescente, decidimos garantir a participação das próprias crianças, de modo que recebemos 600 adolescentes em Brasília, de todos os cantos do País, a fim de discutir de igual para igual as políticas públicas do segmento. E para garantir esse nível de participação, foi preciso obtermos um elevado nível de gestão e planejamento.

A diversidade, portanto, é matériaprima do gestor. E exige, como visto, uma capacidade de adaptação constante: quando vamos a uma comunidade quilombola, quando chegamos ao interior da Amazônia, quando temos de fazer atendimento de pessoas ameaçadas de morte. A gestão de direitos humanos exige uma capacidade política de interlocução permanente, de diálogo permanente e de soluções criadoras e criativas para cumprir os pressupostos que temos diante de nós.

Para irmos além, cabe perguntar: como é possível afirmar direitos humanos sem uma reforma contundente e democrática das polícias no Brasil? A tarefa de direitos humanos está inconclusa. Não há 
possibilidade de seguir avançando sem contarmos com as estruturas do Estado plenamente voltadas aos princípios de direitos humanos. E para isso, temos que, necessariamente, contar com gestores públicos capazes de compreender todas essas dimensões, assim como implementar as políticas públicas que estejam à altura desse desafio. Isso significa que o Governo Federal precisa dar respostas ao povo, superando a violência e produzindo uma cultura de paz, porque direitos humanos, democracia e paz são parte de uma mesma ciranda, que gira em torno da construção da sociedade que queremos e precisamos realizar.

\section{Nota}

${ }^{1} \mathrm{O}$ artigo é baseado no discurso proferido pela Ministra de Estado Chefe da Secretaria de Direitos Humanos da Presidência da República, Maria do Rosário Nunes, na aula inaugural do curso de Especialização em Gestão de Políticas Públicas de Direitos Humanos da ENAP, em 21/8/2013.

Maria do Rosário Nunes é Ministra de Estado Chefe da Secretaria de Direitos Humanos da Presidência da República e mestre em Educação pela Universidade Federal do Rio Grande do Sul (UFRGS). 